\title{
Comentário A \\ “O CONCEITO DE NATUREZA NA FILOSOFIA DE LUDWIG FEUERBACH"
}

José Edmar Lima Filho ${ }^{2}$

Referência do artigo comentado: CHAGAS, E. F. O conceito de natureza na filosofia de Ludwig Feuerbach..Trans/form/açáo: revista de filosofia da Unesp, v. 44, n. 3, p. 51-68, 2021.

O texto de Eduardo Ferreira Chagas tem o mérito de trazer a lume a tematização de um problema bastante caro ao pensamento de Ludwig Feuerbach (1804-1872), porém, ainda năo suficientemente tratado, de maneira articulada, pela literatura especializada que se dedica à sua interpretaçáo, qual seja, o tema da natureza.

Iniciando por uma breve explanaçáo do "estado da arte" dos estudos que abordam o ponto central de seu trabalho, pelo qual restam expostos os contornos dos enfoques de alguns dos mais influentes intérpretes da filosofia

\footnotetext{
${ }^{1}$ Em registro meus agradecimentos ao editor da Revista Trans/Form/Ação, pelo convite à produção do presente comentário.

2 Professor Adjunto do Curso de Filosofia da Universidade Estadual Vale do Acaraú (UVA), Sobral, CE - Brasil. Líder do Grupo de Pesquisas Ludwig Feuerbach e pensamento pós-hegeliano (GPELF/ UVA-CNPq), membro pesquisador do Grupo de Pesquisa em Filosofia da Religião (GEPHIR/UVACNPq) e do Laboratório de Estudos Hegelianos (LEH/UVA-FUNCAP). (D) https://orcid.org/00000003-2564-2651. E-mail: semedmar@yahoo.com.br.
}

https://doi.org/10.1590/0101-3173.2021.v44n3.05.p69 
feuerbachiana, Chagas argumenta pela insuficiência dessas perspectivas, fundamentado no diagnóstico de que estariam fixadas em um isolamento parcial da temática em um determinado período da produção intelectual de Feuerbach, sem a preocupação fundamental de fornecer uma leitura mais transversal do problema, esmerando-se por uma visão de conjunto, que é precisamente o que pretende o texto em comento. Cabe-lhe, então, a proposição de uma tese em vista da qual desenvolverá sua argumentação, que vem apresentada como segue:

Conquanto ele [Feuerbach] não tenha empreendido, infelizmente, uma formulaçáo completa de sua concepçáo de natureza como um todo, isto é, não tenha deixado nenhuma filosofia da natureza explícita e acabada e também não tenha redigido nenhum escrito pormenorizado e sistematizado acerca da natureza, há, todavia, em sua obra, em diferentes passagens, uma abundância de aforismos, epigramas, definitionen e reflexóes filosóficas sobre a natureza. Assim, o conceito de natureza de Feuerbach foi desdobrado, em sua obra, na verdade apenas de maneira fragmentada, mas ele está, apesar disso, no centro de sua filosofia. O desenvolvimento e a transformação desse conceito perpassam, de certa maneira, como fio condutor a totalidade da obra de Feuerbach, abrem um caminho para entendermos a sua filosofia como crítica ao teísmo (Theismus) e ao Idealismo (Idealismus) e nos permitem tratá-la sistematicamente. (CHAGAS, 2021, p. 53-54).

É pela consideração de que o tema da natureza comparece como "fio condutor" da produçáo filosófica feuerbachiana que Chagas (2021) proporciona ao leitor uma valiosa interpretaçáo do problema, embora possa parecer pretensioso fazê-lo por meio de um reduzido número de páginas. Desde logo, portanto, percebe-se que ao autor incumbe uma tarefa complexa, para um trabalho de pequeno fôlego, o que nos leva a concluir se tratar de uma provocaçáo inicial e, talvez, essa constitua a maior lacuna que o texto deixa ver: a de não nos permitir desfrutar mais demoradamente da companhia do autor e, obviamente, do próprio Feuerbach. Se o texto é curto em extensão, não é pequeno seu alcance, entretanto: as páginas que se seguem demonstram náo apenas a inegável erudição de seu autor, como também sua arguta compreensão do pensamento feuerbachiano, o qual, com rigor e profundidade, vai sendo desvelado com a continuidade da leitura de cada linha do trabalho, sempre com o olhar fixo no recorte assinalado.

Importante ressaltar, como um destaque, algo sobre o que o próprio autor parece ter muita consciência: o risco sempre iminente de construir uma 
sistematização para uma abordagem teórica que se quer antissistemática; essa é, diga-se de passagem, uma das mais significativas características do modus operandi, tanto da filosofia especulativa quanto da teologia cristã, que se acham sob a mira de Feuerbach como objetos especiais a criticar. Por isso mesmo, o que Chagas propóe deve ser compreendido bem como tarefa hermenêutica, aliás, propriamente identificada por Feuerbach como uma das atribuiçóes do filósofo (FEUERBACH, 2005a, p. 35).

O outro risco que permanece no texto, esse talvez menos perceptível, é o de tratar o problema da natureza, sem dúvida alguma central para a obra feuerbachiana em geral, encerrando-o em um "conceito", sem as devidas ressalvas, porque o conceito pode (ainda que não necessariamente) ser compreendido como uma simples elaboraçáo intelectual, como uma mera entidade mental e, como tal, como tấo somente uma construção humana. Aliás, é a partir daí que Feuerbach parece compreender o tema da abstração, por exemplo, que daria ensejo à sua formulação de uma "teoria da genericidade" inserta em sua antropologia, para mencionar apenas uma ocorrência da questáo (FEUERBACH, 2012a, p. 35ss). ${ }^{3}$ Por esse motivo, deve-se ter em causa que é certamente tendo em vista a advertência dos Grundsätze (1843) - de que a filosofia "é um ato do sujeito humano" (FEUERBACH, 2005d, p. 153) - que Chagas desdobra seu argumento, pelo qual advoga, em linha com Feuerbach, pela independência e anterioridade da natureza frente ao espírito; isso significa que, stricto sensu, em decorrência dos predicados há pouco mencionados, a natureza escaparia à própria possibilidade de conceituação, pela qual ela se tornaria obra do engenho humano. Por isso mesmo, deve-se flexibilizar aqui a própria noção de "conceito" utilizada no trabalho. Se não a todos, pelo menos a este leitor parece oportuno deixar essa provocaçáo como um destaque, a fim de evitar uma aporia desnecessária e, talvez mesmo, incontornável, salvo melhor juízo.

De todo modo, é inegavelmente significativo o empenho de Chagas (muito bem-sucedido, por sinal) por oferecer ao público um subsídio interpretativo de grande relevância para compreender o problema filosófico da natureza em Feuerbach, exposto em três diferentes momentos, os quais, para seguir a proposta do autor, acompanhariam períodos distintos da produção filosófica feuerbachiana, quais sejam:

\footnotetext{
${ }^{3}$ Embora o caso mencionado no parêntese se refira A Essência do Cristianismo (Das Wesen des Christentums [1841]), não é verdade que constitua um exemplar exclusivo. Mesmo em obras de juventude, como De Ratione Una, Universali, Infinita (1828), essa questão já é trazida à baila (FEUERBACH, 1995).
} 
1. como aproximação crítica ao panteísmo (identidade da natureza com Deus), 2. como recusa direta à teologia cristã e à filosofia hegeliana (a natureza como criaçáo de Deus ou como deduktion do espírito) e 3. como crítica parcial à religião da natureza (antropomorfização ou personificação da natureza). (CHAGAS, 2021, p. 55)

Embora uma compreensão "etapista" da filosofia de Feuerbach tenha se tornado corrente entre os intérpretes, algo que tem razáo suficiente argumentada com propriedade por cada um deles, parece-me que se deve sempre assumila como uma opção didática, pois elementos reconhecidamente presentes em textos de maturidade estariam já anunciados mesmo em textos juvenis por Feuerbach, e vice-versa. Como quer que seja, isso não constitui necessariamente um elemento de objeção no caso específico do exposto por Chagas, porque o desenrolar do argumento justifica a classificação tipológica de que se serve, seja pelo lastro textual que é evocado, seja pelo conjunto da opera feuerbachiana em geral, identificado claramente pelo leitor mais habituado a ela.

Depois de apontar certa "recepção crítica do panteísmo" nos trabalhos feuerbachianos de juventude, Chagas argumenta em favor de uma concepção autárquica de natureza nos escritos do "segundo período" da produção de Feuerbach (1839-1843), quando "não [se] desenvolve [...] nenhuma teoria da natureza, mas [um]a apresenta[ção] indireta[...], para defendê-la contra a atitude cristá frente a ela." (CHAGAS, 2021, p. 58). Isso ocorreria no período indicado em decorrência da constatação feuerbachiana de uma postura negativa do Cristianismo em relação à natureza. É exemplo característico dessa posição a interpretaçẫo feuerbachiana da noçáo cristã de creatio ex nihilo, assim como da doutrina do pecado original (CHAGAS, 2021, p. 8). Com fundamento nessa base textual, Chagas propóe uma hipótese bastante valiosa para uma exegese do tema da natureza no período considerado, particularmente na produção mais conhecida de Feuerbach, qual seja, A Essência do Cristianismo; a juízo de Chagas, não há uma exposição mais demorada da temática da natureza, nessa obra, em razão da

[...] ocupação [de Feuerbach] com o Cristianismo que ignora completamente a natureza e póe em seu cume um Deus pessoal, que cria através do "puro pensar" e do "querer" a natureza, o mundo. Em consequência disso, a natureza foi considerada não enquanto tal; ela não experimenta aqui, na verdade, nenhum tratamento próprio, independente, já que não há no Cristianismo nenhuma autonomia da natureza, nenhuma autarquia e independência dela em relação a Deus. (CHAGAS, 2021, p. 59) 
A hipótese de Chagas permite compreender que a aparente lacuna mencionada é motivada por uma questão fundamentalmente metodológica, suportada, entretanto, no pressuposto de uma compreensão da realidade da natureza como negação da fantasia e da imaginação que povoam, por um lado, a teologia cristá e, por outro, o idealismo alemão, representado no artigo pela referência a Hegel, para quem "[...] a natureza está subjugada ao espírito" (CHAGAS, 2021, p. 59) - embora se reconheça certa aproximação entre Feuerbach e Schelling (CHAGAS, 2021, p. 10).

O ponto seguinte do artigo de Chagas permite uma imersão nos chamados "escritos de maturidade", ao seu entender identificados desde 1846-1848 - em que comparece a crítica feuerbachiana da "natureza como objeto da religiáo" - até aos textos do final da década de 1860, quando há, segundo Chagas, uma tentativa de "fusão" entre filosofia e ciências da natureza (CHAGAS, 2021, p. 10-11). Desse período final abordado no trabalho, resta posto que Feuerbach intencionaria

[...] superar todo discurso (oratio) antropológico, teleológico ou teológico em relação à natureza, ou seja, obter a separaçáo da mesma da reductio ad hominem, de todos os predicados humanos. Assim, ele fez a si, por tarefa, defender, justificar e fundamentar a autarquia, a autonomia da natureza "contra os esclarecimentos e as deduçóes teológicas" frente a ela. (CHAGAS, 2021, p. 61).

É nesse momento da produção intelectual de Feuerbach que se apresenta o interesse por desenvolver, entre outras, a tese do "sentimento de dependência" do homem em relaçáo à natureza, a qual, ao tempo em que revela o reconhecimento da anterioridade e imprescindibilidade desta para a existência real do ser humano, de igual maneira contribui para alargar a sua compreensão como instância independente do espírito. Trata-se, portanto, de fomentar uma concepção de natureza que não dependa necessariamente de uma antropologia prévia ou de uma teorização religiosa. Não sem razão que Feuerbach se sirva dessa tese para demonstrar a reação cada vez mais evidente de seu pensamento com respeito à teologia cristã e ao idealismo.

Encaminhando-se para a finalização do artigo, Chagas verifica a aproximação progressivamente mais produtiva que Feuerbach busca promover entre as ciências da natureza e o próprio fazer filosófico, não sem retomar o tema da cultura e da ciência como frutos da engenhosidade humana, que Feuerbach parece não ter estado disposto a abandonar. Mas um elemento das 
consideraçôes finais merece maior visibilidade: o reconhecimento, indicado por Chagas, da ausência de uma "dimension social, histórico-concreta" na proposta feuerbachiana, que se esmere por uma tematização das "condiçóes materiais, sociais e econômicas" da sociedade.

Chagas tem razáo, quando atesta a inexistência de um tratamento mais vertical de determinadas questóes "econômicas" as quais definiriam, ao que parece, aquilo que compreende como uma "dimensão social históricoconcreta" e que desembocasse numa tematização mais comprometida de questóes materiais e sociais. A propósito, essa aparenta ser uma das indicaçóes da leitura marxiana de Feuerbach, amplamente difundida na Academia, pela qual muitos concluem pela desimportância da filosofia feuerbachiana, fixandose e interessando-se, quando muito, apenas pelo "Feuerbach de Marx". Valeria a pena, portanto, gastar alguma energia para elencar alguns pontos que, como penso, requerem certa notoriedade, não necessariamente como uma oposição a Chagas, mas certamente como uma provocação para suscitar do leitor um interesse mais vívido pela continuidade da leitura das próprias obras de Feuerbach, para o que inclusive contribui estruturalmente o trabalho de Chagas, seja o presente, seja o de suas outras tantas importantes produções.

Em primeiro lugar, há que se ter em consideração que Feuerbach colabora para que se reconheça a importância fundamental da história para a produçáo de uma filosofia "[...] que fale o idioma humano" (FEUERBACH, 2012a, p. 21) e principie por um começo real $l^{4}$, não abstrato, o que o faz se dirigir, por um lado, contra a concepção especulativa de história (particularmente a de Hegel: FEUERBACH, 2012b, p. 24), bem como para mostrar a fidelidade entre a filosofia e a sensibilidade, de modo que se torne a filosofia "[...] traduzida em succum et sanguinem, em carne e osso, a filosofia encarnada em homem" (FEUERBACH, 2012a, p. 21). Daí a importância, desde os escritos de juventude, por ressaltar uma filosofia como "[...] ensarcose ou a encarnação do Logos puro" (Carta a Georg Wilhelm Friedrich Hegel [22 de novembro de $\left.1828^{5}\right]$ ), assim como por viabilizar uma concepção de história para além da simples temporalidade, mas que aceite igualmente a espacialidade, tornandose uma "história situada", erguida sobre uma ontologia muito particular, que

\footnotetext{
${ }^{4}$ A respeito do tema do começo para o filosofar: Feuerbach (2005b, p. 78-79; 2012b, p. 40ss).

${ }^{5}$ Uso aqui a tradução portuguesa de Serrão (2019, p. 244).

${ }^{6}$ Daí Arvon sustentar, com base em Feuerbach, que "[...] o espaço e o tempo são solidários; não se pode apreender a sucessão sem o concurso da simultaneidade. Uma visão exclusivamente temporal, ou seja, histórica, não pode explicar a natureza." (ARVON, 1957, p. 41).
} 
pode ser compreendida, segundo penso, como "ontologia da singularidade" (LIMA FILHO, 2019).

Isso significa que a própria filosofia de Feuerbach se insere, como ele mesmo admite, como uma urgência de sua época histórica, à qual pretende responder - inclusive com a proposta de uma "transformação" da própria filosofia. ${ }^{7} \mathrm{Se}$, em sua avaliação, o momento histórico ressaltava a sobrevalorização do supranaturalismo, seja pela filosofia especulativa, seja pela teologia, sua filosofia procura promover a "[...] divinização do real, do que existe materialmente - o materialismo, empirismo, realismo, humanismo -, a negação da teologia, [...] [algo que corresponde à] essência dos tempos modernos." (FEUERBACH, 2005d, p. 116).

A consequência dessa posição é que Feuerbach sugere uma filosofia $d a$ imanência e do presente - embora seja prospectada para of futuro (FEUERBACH, 2005d, p. 101) -, presente este considerado desde sua juventude como "consolo do hoje” (FEUERBACH, 1995b, p. 167), para afirmar a importância da vida real, caracterizada pela fugacidade e unicidade (FEUERBACH, 1995b, p. 184). É exatamente aí que se justifica o materialismo feuerbachiano, ao mesmo tempo presentificado no agora histórico e no vínculo inextricável com a natureza, embora esteja de alguma maneira marcado por certo otimismo ou progressismo. ${ }^{8}$

Em segundo lugar, parece importante colocar em evidência a preocupação feuerbachiana por um modo de filosofar que reconheça a alteridade e, consequentemente, que se desloque de uma filosofia do "eu puro"

7 Há muitas ocasiōes em que Feuerbach faz referência a esse elemento e, por isso, Serrão adverte que "[...] a necessidade de uma transformação na filosofia é anunciada [por Feuerbach] como uma exigência do tempo e não como imperatividade interna à filosofia." (SERRÃO, 2005, p. 26). A título de exemplo: Feuerbach (2005c, p. 157ss).

${ }_{8}$ Amengual argumenta que "Feuerbach compartilha com o pensamento criticado o pressuposto de um progressismo, a história como progresso, que em parte é assimilado reinterpretando-o em sentido negativo (a história como progressivo distanciamento da natureza é entendida como história de excisão e alienação), em parte é mantido em contradição com o esquema global, e em parte é negado, enquanto o retorno à natureza não é propriamente um processo histórico, senão uma reinterpretação e uma tomada de consciência [...]. Para Feuerbach a história não pode ser nunca propriamente história universal. Aí se dá uma autêntica contradictio in terminis. A história conhece unicamente sucessão e subordinação; embora se fale de totalidade, esta não é mais que uma particularidade considerada como resumo que subsume todas as demais. A natureza [...] conhece a coordenaçấo e a coexistência, nela se dá a verdadeira totalidade, a totalidade em sua verdade e realidade. Dar-se-á, pois, universalidade com o retorno à natureza. Pode-se dar, pois, uma Weltnatur, mas não uma Weltgeschichte, pois sempre implicará subordinação de uns sob outros. A universalidade se dará com o retorno à natureza." (AMENGUAL, 1982, p. 66). 
para abrir-se em uma perspectiva dialógica, passando necessariamente por uma concepção relacional do ser humano e, portanto, por admitir sua sociabilidade. Desde o reposicionamento do cogito cartesiano, em sua tese de habilitação para a docência, ${ }^{9}$ até os textos de maturidade, passando pelas obras assim compreendidas como "de transição" - para fazer referência ao "etapismo" ou "periodismo" admitido pela literatura secundária sobre o que já me pronunciei - Feuerbach desenvolve uma maneira de pensar que, uma vez fortalecida pelo pressuposto do assentimento da intersubjetividade, propóe uma espécie de socialidade humana tratada, seja em certa concepção de comunidade, seja em uma concepção política que desemboca em mençôes ao Estado e, ao que tudo indica, em uma ideia de República e de democracia (MARTÍNEZ, 2009), embora sejam intuiçóes que, certamente, mereceriam maior aprofundamento da parte do próprio Feuerbach. De fato,

[...] nas "Teses provisórias para a Reforma da Filosofia" ("Vorläufige Thesen zur Reformation der Philosophie" [1842]) Feuerbach se limita a mencionar a noção de "Estado" e de fazer referência a um "chefe do Estado" que deve representar a todos os estratos sociais, mas não se detém na avaliação do tipo de organização estatal a que este conceito corresponde (cf. FEUERBACH, 2005f, p. 100). Em "Principios da filosofia. Necessidade de uma transformaçâo", a referência ao Estado é retomada apelando para a noção de associatividade, de complementaridade que aperfeiçoa o homem (cf. FEUERBACH, 2005c, p. 162), e no mesmo texto Feuerbach menciona a ideia de república terrena como efeito da oposição à "república no céu” (cf. FEUERBACH, 2005c, p. 168), além de rapidamente versar sobre uma comunidade não-hierárquica como um "impulso prático" que move a Humanidade (cf. FEUERBACH, 2005c, p. 166). É igualmente interessante que a Carta a Otto Wigand, datada de 03 de março de 1848, seja iniciada pela expressão "Vive la République?" e que nela Feuerbach reconheça que a Revoluçáo Francesa lhe tenha causado uma revolução interna (cf. FEUERBACH, 1904, p. 156). Além disso, Schneider ainda acentua que Feuerbach teria confessado a forma de estado republicano a Karl Riedel (cf. SCHNEIDER, 2013, p. 13). (LIMA FILHO, 2018, p. 30-31 - nota 30).

Essas referências fazem notar que, não obstante seja um lugar-comum a indicação da inexistência de uma tematização política no pensamento de

\footnotetext{
9 Em De Ratione, afirma Feuerbach: "Penso, logo sou todos os homens." (FEUERBACH, 1995a, p. 127).
} 
Feuerbach, assim como a ausência de certas motivaçôes sociais, ${ }^{10}$ ela não parece se alinhar com exatidão ao que está manifesto em diversos momentos de sua produção intelectual. Esse é um tema que, obviamente, mereceria ser examinado com maior rigor por um estudo à parte. Por ora, fica apenas mais esse registro.

Em terceiro lugar, um último elemento importante de ressaltar é que, se Feuerbach não elabora um esquadrinhamento mais radical da realidade sociopolítica que envolva uma exposição mais detalhada sobre elementos econômicos - o que é de se lamentar, dada a envergadura de sua filosofia -, comparecem em certas passagens de sua obra referências diretas, embora pontuais, a essa questão, o que parece sinalizar que Feuerbach não as desconhecia ou que as desconsiderasse em absoluto, na sua formulação filosófica.

Exemplos claros a esse respeito são localizáveis nas obras de maturidade, particularmente em Sobre a Filosofia Moral (Zur Moralphilosophie [1868]), quando Feuerbach declara que

[...] não existe felicidade sem virtude [...] Mas tenha-se bem em mente: náo existe igualmente virtude sem felicidade - $\mathrm{e}$ com isto a moral adentra no âmbito da economia privada e da economia política. Onde não são dadas as condições para a felicidade, também não há condiçôes para a virtude. (FEUERBACH, 1992, p. 59).

Nota-se, do exemplo acima, que Feuerbach não apenas reconhece a importância da economia para a felicidade, todavia, por compreendê-la a partir de seu vínculo com a virtude, também para a moral. ${ }^{11}$ Isso não seria possível similarmente sem a percepção de uma relação estreita do homem com a natureza, pois é a natureza a instância originária, a conditio sine qua non para a existência real do ser humano concreto. Daí que Feuerbach, inclusive fazendo menção a Marx, indique que

\footnotetext{
${ }^{10}$ Schmidt chega a assinalar que "[...] o antropologismo de Feuerbach contém motivos sociais que, criticamente elaborados, passaram à teoria marxiana” (SCHMIDT, 1975, p. 210), embora lhe seja estranha uma "sociologia materialista" (SCHMIDT, 1975, p. 212).

${ }^{11}$ Por isso, tive ocasiāo de ressaltar em outra oportunidade que, "[...] na medida em que se refere à relação da discussão moral com o cômputo próprio da economia, seja privada, seja política, Feuerbach parece inserir no argumento sobre as condiçōes para a felicidade e a virtude a noção de condiçóes materiais, posto que este é o âmbito de atuação da economia." (LIMA FILHO, 2018, p. 32).
} 
[...] a virtude necessita, como o corpo, de nutrição, roupas, luz, ar, espaço. Onde os homens são esmagados, uns sobre os outros, como, por exemplo, nas fábricas e nas casas de trabalhadores ingleses, admitindo-se que se possam chamar de casas aquelas pocilgas onde mesmo o oxigênio do ar não vem dividido em medida suficiente - compare-se a este propósito o escrito de K. Marx O Capital, rico de fatos incontestáveis e instrutivos, bem como de pensamentos reformadores da espécie mais interessante, mas também mais terrível -, aqui também é retirado da moral todo espaço de ação, aqui a virtude é, no máximo, apenas um monopólio dos senhores proprietários das fábricas, dos capitalistas. Onde falta o necessário à vida, falta também a necessidade ética. $\mathrm{O}$ fundamento da vida é também o fundamento da moral. (FEUERBACH, 1992, p. 59-60).

Pelo que se depreende dos elementos adicionais colocados em realce, no presente comentário, eles em nada prejudicam a relevância e a necessária exposição de Chagas sobre o tema da natureza, até porque se concentram em questôes externas à intenção originária do artigo comentado. $\mathrm{Na}$ verdade, o propósito não é senão (i) reforçar a proposta hermenêutica do autor em comento e, (ii) mesmo que introdutoriamente, estimular o leitor a examinar com maior comprometimento a importante contribuição feuerbachiana, infelizmente ainda muito desconhecida entre nós.

\section{REFERÊNCIAS}

AMENGUAL, G. Crítica al pensar histórico y naturalismo en L. Feuerbach. Taula. Quaderns de Pensament, Universitat de les Illes Balears, n. 1, p. 53-66, 1982.

ARVON, H. Ludwig Feuerbach ou la transformation du sacré. Paris: Presses Universitaries de France, 1957.

CHAGAS, E. F. O conceito de natureza na filosofia de Ludwig Feuerbach..Trans/form/ açáo: revista de filosofia da Unesp, v. 44, n. 3, p.51-68 2021.

FEUERBACH, L. Etica e felicità. Con una raccolta di aforismi di argomento morale ${ }^{12}$. Trad. it. Barbara Bacchi. Milano: Guerini e Associati, 1992.

FEUERBACH, L. De Ratione, Una, Universal, Infinita. In: FEUERBACH, L. Abelardo y Heloísa y otros escritos de juventud. Trad. cast. José Luis García Rúa. Granada: COMARES, 1995a. p. 73-139.

${ }^{12}$ Esse texto compreende a traduçấo italiana editada por Ferrucio Andolfi da obra feuerbachiana, publicada postumamente por K. Grün, com o título Zur Moralphilosophie, e W. Bolin e F. Jodl, que o intitularam Der Eudämonismus. 
FEUERBACH, L. Epigramas teológico-satíricos (1830). In: FEUERBACH, L. Abelardo y Heloísa y otros escritos de juventud. Trad. cast. José Luis García Rúa. Granada: COMARES, 1995b. p. 141-265.

FEUERBACH, L. A Karl Riedel. Para a rectificação do seu esboço. In: FEUERBACH, L. Filosofia da Sensibilidade. Escritos (1839-1846). Trad. port. Adriana Veríssimo Serrão. Lisboa: Centro de Filosofia da Universidade de Lisboa, 2005a. p. 33-41.

FEUERBACH, L. Algumas consideraçóes sobre O começo da filosofia do Dr. J. F. Reiff. In: FEUERBACH, L. Filosofia da Sensibilidade. Escritos (1839-1846). Trad. port. Adriana Veríssimo Serrão. Lisboa: Centro de Filosofia da Universidade de Lisboa, 2005b. p. 77-84.

FEUERBACH, L. Princípios da filosofia. Necessidade de uma transformação. In: FEUERBACH, L. Filosofia da Sensibilidade. Escritos (1839-1846). Trad. port. Adriana Veríssimo Serrão. Lisboa: Centro de Filosofia da Universidade de Lisboa, 2005c. p. 157-169.

FEUERBACH, L. Princípios da filosofia do futuro. In: FEUERBACH, L. Filosofia da Sensibilidade. Escritos (1839-1846). Trad. port. Adriana Veríssimo Serrão. Lisboa: Centro de Filosofia da Universidade de Lisboa, 2005d. p. 101-155.

FEUERBACH, L. A Essência do Cristianismo. Trad. bras. José da Silva Brandão. Petrópolis: Vozes, 2012a.

FEUERBACH, L. Para a crítica da filosofia de Hegel. Trad. port. Adriana Veríssimo Serrão. São Paulo: LiberArs, 2012 b.

LIMA FILHO, J. E. Elementos para uma reflexão política em Feuerbach: uma aproximação inicial ao problema. Revista Reflexóes. Fortaleza, ano 7, n. 13, p. 11-42, jul./dez. 2018.

LIMA FILHO, J. E. Ontología de la singularidad y el problema del lenguaje en Ludwig Feuerbach: para una lectura de Zur Kritik der Hegelschen Philosophie (1839). Revista El Arco y la Lira. Tensiones y Debates. Buenos Aires, v. 7, p. 19-33, 2019.

MARTÍNEZ, J. G. Un aporte a la filosofía política desde la ética de Ludwig Feuerbach. Presente, pasado y futuro de la democracia, Universidade de Murcia, p. 213-220, 2009.

SCHMIDT, A. Feuerbach o la sensualidad emancipada. Trad. esp. Julio Carabańa. Madrid: Taurus, 1975.

SCHNEIDER, K. Zum Geleit: "Vive la République" - Der politische Feuerbach. In: SCHNEIDER, K. (Hrsg.) Der politische Feuerbach. Münster/New York/München/ Berlin: Waxmann, 2013. p. 13-18.

SERRÃO, A. V. Apresentação. In: FEUERBACH, L. Filosofia da Sensibilidade. Escritos (1839-1846). Trad. port. Adriana Veríssimo Serrão. Lisboa: Centro de Filosofia da Universidade de Lisboa, 2005. p. 13-30.

Recebido: 05/8/2020

Aceito: 08/8/2020 
LIMA FILHO, J. E. 